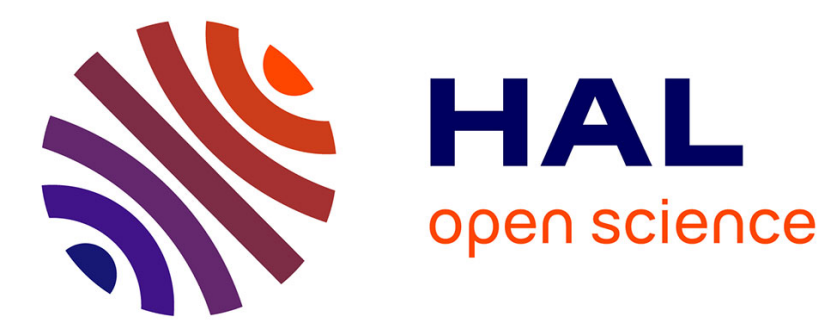

\title{
The reform of European securities settlement systems : Towards an integrated financial market
}

Marie-Noëlle Calès, Dominique Chabert, Walid Hichri, Nadège Marchand

\section{To cite this version:}

Marie-Noëlle Calès, Dominique Chabert, Walid Hichri, Nadège Marchand. The reform of European securities settlement systems : Towards an integrated financial market. 2011. halshs-00639957

\section{HAL Id: halshs-00639957 \\ https://shs.hal.science/halshs-00639957}

Submitted on 10 Nov 2011

HAL is a multi-disciplinary open access archive for the deposit and dissemination of scientific research documents, whether they are published or not. The documents may come from teaching and research institutions in France or abroad, or from public or private research centers.
L'archive ouverte pluridisciplinaire HAL, est destinée au dépôt et à la diffusion de documents scientifiques de niveau recherche, publiés ou non, émanant des établissements d'enseignement et de recherche français ou étrangers, des laboratoires publics ou privés. 
The reform of European securities settlement systems: Towards an integrated financial market

Marie-Noëlle Calès, Dominique Chabert, Walid Hichri, Nadège Marchand

Novembre 2011 


\section{GATE Groupe d'Analyse et de Théorie Économique Lyon-St Étienne}

93, chemin des Mouilles 69130 Ecully - France

Tel. +33 (0)4 72866060

Fax $+33(0) 472866090$

6, rue Basse des Rives 42023 Saint-Etienne cedex 02 - France

Tel. +33 (0)4 77421960

Fax. $+33(0) 477421950$

Messagerie électronique / Email : gate@gate.cnrs.fr

Téléchargement / Download : http://www.gate.cnrs.fr - Publications / Working Papers 


\title{
The reform of European securities settlement systems: Towards an integrated financial market
}

\author{
Marie-Noëlle Calès, Dominique Chabert† Walid Hichrił Nadège Marchand ${ }^{\S}$
}

November 7, 2011

\begin{abstract}
The European Central Bank (ECB) will offer to banks in 2013 an european shared platform for securities settlement, named TARGET 2 Securities (T2S), in order to open the national financial markets. The financial crisis did not change the ECB agenda. This paper develops a spatial competition model to understand the impact of this new organisation on european post-trading services. We analyse the incentives of the Central Securities Depositaries (CSD) to move to $\mathrm{T} 2 \mathrm{~S}$ when they become competitors in the market for settlement services and remain in a monopoly position for depository services. Settlement and depository services are complementary goods, because banks have to pay for these two services to buy or sell a security. We show that such a reform should induce a decrease in the settlement price and more generally in post-trading prices, but that prices depend strongly on market organisation. Under certain conditions, partial adhesion would make prices increase. This configuration appears as a Nash equilibrium. As CSDs are free to adhere to T2S, the ECB might be forced to regulate.
\end{abstract}

JEL classification: D43; G15; G20.

Keywords: Post-trading organisation, securities settlement, depositary services, compatibility

\footnotetext{
* corresponding author : GATE-CNRS, Université Lyon 2, 93, chemin des Mouilles, B.P.167, 69131, ECULLY, France. cales@gate.cnrs.fr, tel: +33 (0)4 728660 70, Fax: +33 (0)4 72866090.

${ }^{\dagger}$ University of Lyon, Lyon, F-69007

$\ddagger$ University of Lyon, Lyon, F-69007

$\S$ University of Lyon, Lyon, F-69007
} 


\section{Introduction}

The recent financial crisis has underlined some limits of the liberalisation of financial markets, as managed for 20 years in Europe. This liberalisation has induced in the 90's a strong competition between the market institutions. And the European financial infrastructures have been the theatre of important mergers such as NYSE and Euronext, Euroclear and Sicovam for example. Recently, Deutsche Börse and NYSE Euronext have announced they were going to merge ${ }^{1}$. This vast movement of consolidation has been encouraged by the European Commission and the European Central Bank (ECB) who seek to establish a unified market for the issuance and trade of financial securities across the EU. Nevertheless, European countries failed to unify their financial markets. The two Giovaninni Reports $(2001,2003)$ have identified the main barriers to the emergence of unified market infrastructures. Among them, the fragmented post-trading systems create a bottleneck which discourages cross-boarder trades by generating higher costs compared to the US market (see Lannoo and Levin, 2001, for empirical studies).

The post-trading infrastructures refers to the trading treatment of securities. Three operations have to be realised after negociation: clearing, settlement and book-keeping. These operations are located at the end of the trading treatment; all securities bought on financial market have to be transferred from the account of the seller to the account of the buyer and recorded in the book-keeping of a Central Securities Depositary (CSD). The first operation (associated with cash transfer) is called settlement. The second operation, named depositary service, appears as a typical notary function, so that a CSD is a kind of national central bank for securities. Generally, an unique firm manages settlement and depository services in every country and this situation is a result of the history of markets. Settlement has been gradually captured by CSDs, such that settlement and depositary activities appear today as two bundling services. In some cases, before settlement and book-keeping, securities can be cleared by specialised institutions (clearing houses), whose main interest is to act as a global netter. Clearing houses demand collateral (deposit in cash or in securities), so that it reduces the risk. The clearing is not mandatory, whereas, settlement and depository are necessarly realised after a deal.

Such industry faces high fixed costs due to important investments in software (up-grade), network security and backup of data. Hence, securities settlement services should be highly concentrated (see Schmiedel, Malkamaeki, Tarkka, 2006 and Van Cayseelee, Wuyts, 2007). Nevertheless, in the last decade, market forces failed to harmonize and integrate settlement services in Europe. Consequently, securities remained issued (settlement and book-keeping) by domestic CSDs. The constant research of costs saving, of large volume of payments, and the management of cross-border operations force to modernize the settlement securities system in the Euro area (Van Cauwenberge, 2003, Schmiedel, Schonenberger, 2005 and Serifsoy, Weiss, 2007). As mentionned in the Giovanini reports, "there is a consensus within the Group that the EU clearing and settlement landscape could be significantly improved by market-led convergence in technical requirements/market practice

\footnotetext{
${ }^{1}$ Financial Times, February 152011
} 
accross national systems. This would provide for inter-operability between national systems and could deliver considerable benefits within a significantly shorter timeframe than that required for full systems merger."

As no market solution have appeared despite the ECB encouragements, it decided to extend TARGET, the European real-time gross settlement platform, to securities settlement with TARGET 2 securities ${ }^{2}$ (also named T2S) in 2013. Despite the recent financial crisis, the ECB decided to maintain its agenda for $\mathrm{T}_{2} \mathrm{~S}^{3}$. This reform will certainly be determinant in the future of the financial market organisation in Europe because it will challenge the current "silo model "." The priority of the ECB remains the integration of European markets and, moreover, the reforms induced by the financial crisis will have to take into account the T2S.

In the mind of the ECB, T2S will be a shared post-market infrastructure and it should solve the inefficiencies of the current national silo organisation. It must be emphasised that only settlement services will be technically concerned by this new platform. For the European Central Bank, unifying settlement among European countries is easier than depository services because it refers to technical constraints. Depository services are related to fiscal policies and property rights which remain the prerogative of each European state. No agreement seems possible in the next future, even though a European CSD would certainly be a good way to encourage pan-European transactions. But as depositary and settlement services are selling par one unique firm in every country, the depository will certainly be also impacted by this reform .

To our knowledge, no article has ever treated the question of T2S on post-trading markets. Till now, the ECB did not precisely set concrete terms of adhesion to T2S. But according to available information, the ECB should not force each CSD (from the Euro zone) to join the platform T2S. So we can imagine a first scenario in which all CSDs might choose to make their settlement systems compatible together in order to access to T2S. But another scenario is possible, perhaps more realistic, in which some CSDs will decide to stay outside the platform refusing to become compatible.

In this article, we analyse the competition between CSDs for securities settlement and depository services, following the setting up of T2S. With T2S, CSD's become competitors on the market of settlement services, but they remain in a monopoly position for depositary services. This paper develops a spatial competition model to understand the impact of this new organisation on European post-trading services. Our study focuses on the Euro-zone CSDs and deals with the following questions: will T2S imply a decrease in post-trading prices as expected by the ECB and banks? How CSDs will adapt their pricing on settlement and depository services according to compatibility regimes? What will be T2S' market shares if some CSDs do not adopt the platform? One should observe a decrease in the settlement price and more generally in post-trading prices.

\footnotetext{
2i.e. Trans-european Automated Real-time Gross settlement Express Transfer

${ }^{3}$ Trichet, J.C., DECISION OF THE EUROPEAN CENTRAL BANK of 20 April 2011, On the selection of TARGET2-Securities network service providers, Official Journal of the European Union, 21052011.

${ }^{4}$ In a silo organisation which is dominant in Europe,every CSD has a sort of monopoly access to its national market place, because domestic securities are recorded and settled in a unique CSD, the domestic CSD.
} 
But our main results show that prices depend strongly on market organisation (i.e. compatibility regime and competition management).

The continuation of the article is organised as follows. The Section 2 presents the spatial competition model of post-trading services. Section 3 then reports the theoretical conjectures for each compatibility design. The compatibility organisation model results are compared in Section 4 and conclusions are drawn with respect to the market structures. In particular, we analyse these results on the ECB point of view and the european CSDs' incentives to join T2S.

\section{The spatial competition model}

Our model is based on Salop (1979), the spatial modelling of product differentiation. In the spirit of Matutes and Padilla (1994) ${ }^{5}$, we investigate on the implications of the settlement systems compatibility for pricing policy and market shares of settlement and depositary activities. We consider that each transaction on stock exchange needs to be settled and recorded in a CSD account, so that depository and settlement services are perfectly complementary, contrary to the model of Matutes and Padilla. We assume that there are $\mathrm{N}$ banks uniformly distributed over a unit circle with three CSDs in arbitrary location. This circle represents the financial markets of the Euro-zone. This area is fragmented in the sense that each stock exchange has a national CSD (silo-organisation). We consider that each of the $\mathrm{N}$ banks transacts an average identical number of operations. And that each of them has to record the corresponding securities in a CSD. "Naturally", the bank settles its transactions with the same CSD (bundling services).

Each CSD competes for post-trade services of the transactions located in its two neighbourhoods. If a bank is in the neighbourhood of a CSD, this means that it mainly buys securities of the corresponding financial market. Thus, $q_{i, j}$ indicates the quantity captured by the CSD $i$ when competing with CSD $j$ with $i \neq j$. The total quantity of depository services sold by a CSD $i$ at price $p_{i}^{D}$ is noted $q_{i}^{D}$ with $q_{i}^{D}=q_{i, j}^{D}+q_{i, k}^{D}$ with $j \neq k$. For securities settlement, these values are noted $p_{i}^{S}$ and $q_{i}^{S}$ respectively. Each CSD $i$ bears a high fix cost, $C_{i}$, and a variable cost $c_{i}$, which can be separated by activity. Therefore, the proportion of $c_{i}$ generated by the production of depository service is noted $u$ and $v$ for securities settlement, with $u+v=1$. The CSD's total profit corresponds to :

$$
\pi_{i}=p_{i}^{D} q_{i}^{D}+p_{i}^{S} q_{i}^{S}-c_{i}\left(u q_{i}^{D}+v q_{i}^{S}\right)-C_{i}
$$

for $i=1,2,3$.

In order to evaluate the impact of $\mathrm{T} 2 \mathrm{~S}$ on post-trading organisation, we need to study a first case, in which securities settlement systems are incompatible. This case (named "incompatible case") can be interpreted as a schematic representation of the current post-market infrastructures. Then, we investigate the consequences of the reform for the Euro zone CSDs. In the "compatible case",

\footnotetext{
${ }^{5}$ They adopt this approach to analyse the consequences of compatibility of ATM on competition for deposits in banks. For a similar analysis on phonebanking, see Bouckaert and Degryse (1995).
} 
the Euro zone CSDs are free to join the platform and all of them do it, so that their settlement systems become compatible. But we think that, as the European Central Bank will not force the CSDs to use T2S, some of them will choose to stay outside the platform and to remain incompatible with other CSDs. We denote this third design as "partially compatible case" in the following.

For each compatibility scheme, CSDs simultaneously (and independently) choose depository and settlement prices. We simply assume that a bank will buy these two services for each deal to a CSD in its neighbourhood. Given the lack of counterpart risk, for a precise CSD network size, banks always prefer lower prices. Travelling costs associated to each service are $t^{D}$ and $t^{S}$, respectively for depositary and settlement services, with higher cost for settlement, i.e. $t^{D}<t^{S}$. Settlement service seems to be more costly because of safety constraints and complexity of technical connexions. The more the security is complex, the more the travelling cost is important.

Sometimes banks set deals on non-domestic stock exchanges. Hence, banks have to settle and record foreign securities and the costs are growing up. So, they need post-trading services from "foreign" CSD with positive probability, $p$. Indeed, banks must use the CSD. We consider that the domestic CSD of a bank is determined by its location on the circle and that the CSD of a security is determined by the nationality of the security. of the foreign security, especially for the depositary service (because of its legal function). But, as the settlement and the depositary services are bundling services, the two operations must be delivered by the same CSD. To access to a CSD, a bank must be one of its members and have to pay a membership cost which is rather high. We consider that these costs are equal for each CSD, so that we can ignore them in our model. Moreover, banks are not member of each CSD because it would be too expensive and they don't use CSDs'interlinks which are too costly ${ }^{6}$.

That's why they generally prefer to be member of one unique CSD for domestic deals and they use correspondant banks for non domestic deals. We call a domestic deal an operation on a security which is realised on the domestic financial market, for example a french bank buy (or sell) a security which is on Euronext, which has links whith Euroclear (the french CSD). For a security which is on the Deustche Börse, we call that a non domestic deal. In this case, the banks have to go through their correspondant bank which is a member of the german CSD and they support a specific extra cost, noted $C_{S}$. With T2S, banks will be able to settle their cross-border securities directly with foreign CSDs, without being a member: this is one of the major targets of this reform. But they will be obliged to go back to their correspondant bank for depositary service.

Supposing, for instance, that each bank has a positive probability of dealing sometimes with any place of the circle (i.e. a Spanish bank doing a transaction either on the German or French stockexchange), in any of the three CSDs neighbourhoods. If CSDs' securities settlement systems are compatible, the expected travelling cost is lower because the bank can go to the nearest CSD instead of having to go back to its correspondant bank. A network effect appears because the more CSDs are sharing their settlement systems, the greater the utility bank derives from its domestic

\footnotetext{
${ }^{6}$ For an interesting discussion about CSDs'interlinks, see Kauko (2004)
} 
CSD. And there is a trade-off between this network effects and a substitution effect based on prices comparison between CSDs, according to compatibility regimes for settlement services

Let $k(i)$ be the expected extra costs of post-trading services for a foreign security, where $i$ is the number of CSDs to which the bank can process cross-boarder transactions. These costs are equal to the probability of foreign deals, $p$, multiplied by the extra cost $C_{s}$, and the expected distance ${ }^{7}$. The expected distance falls with each additional compatibility CSD. Therefore, the more CSDs are compatible with each other, the lower $k(i)$, i.e. $k(1)>k(2)>k(3)$. Note that the two services support these costs for cross-boarder operations. But contrary to depository service, which can only be done through the CSD of the security, banks may choose any compatible CSD for securities settlement. So, for depositary service, this cost is constant and always equal to $k(3)$, while, for settlement service, it is decreasing with the number of CSDs which become compatible.

$<$ Insert Figure 1 $>$

\section{The effects of securities settlement services design on post- trading}

In the following, we investigate market sharing, optimal pricing of post-trading services and corresponding profit for CSDs in the three following market designs. Firstly, in the incompatible case, banks are forced to make operations of securities settlement and depository services with the same CSD. Cross-border deals are possible at high post-trading costs. Secondly, the compatible case corresponds to the migration of all CSDs to T2S. In our model, all CSDs migrate to T2S and make their settlement systems compatible. Hence, banks can settle a security either with the CSD of the security or with another one. Finally, we investigate the partial compatible design. This last case implies that the migration of CSDs to T2S is incomplete, i.e. only some CSDs decide to migrate to T2S.

\subsection{Incompatibility of the securities settlement services}

According to our previous assumptions, identical CSDs expect the same market shares. We denote them $x=\frac{q_{i, j}^{S}}{N}$ and $y=\frac{q_{i, j}^{D}}{N}$ respectively for settlement and depository services. The marginal operation that the CSD $i$ will be able to capture in competition with CSD $j$ leads to this following rule of market sharing : ${ }^{8}$

$$
2 k(1)+p_{i}^{D}+p_{i}^{S}+t^{S} x+t^{D} y=2 k(1)+p_{j}^{D}+p_{j}^{S}+t^{S}(1-x)+t^{D}\left(\frac{1}{3}-y\right)
$$

\footnotetext{
${ }^{7}$ We obtain easily : $k(1)=3 p C s / 4 ; k(2)=5 p C s / 12 ; k(3)=p C s / 4$

${ }^{8}$ Note that $q_{i, j}^{D}=\frac{N}{3}-q_{j, i}^{D}$. We obtain the same condition for the settlement.
} 
For cross-boarder deals, banks have to support specific extra-costs, which are the same for the two services by assumption and equal to $\mathrm{k}(1)$ in this case. As depository and settlement services must be bought to the same CSD in this design, $x=y$. The quantity sold by one CSD $i$ in competition with $\mathrm{j}$ is $q_{i, j}^{D}=q_{i, j}^{S}=\frac{N}{2 T}$. $\left(p_{j}^{D}-p_{i}^{D}+p_{j}^{S}-p_{i}^{S}\right)+\frac{N}{6}$, with $t^{S}+t^{D}=T$. At the equilibrium, the quantity of post-trading services sold by CSD $i$, which results from the market sharing with CSD $j$ and $k$, is $q_{i}^{D}=q_{i}^{S}=\frac{N}{2 T}\left(p_{j}^{D}+p_{k}^{D}-2 p_{i}^{D}+p_{j}^{S}+p_{k}^{S}-2 p_{i}^{S}\right)+\frac{N}{3}$, with $i, j, k=1,2,3$ and $i \neq j \neq k$.

By equalizing to zero the partial derivative of the CSD $i$ 's profit relatively to $p_{i}^{S}$, we obtain the reaction function of the rational CSD $i$ :

$$
p_{i}^{S}\left(p_{j}^{S}, p_{k}^{S}\right)=\frac{T}{6}+\frac{p_{j}^{S}+p_{k}^{S}}{4}+\frac{c_{i}-p_{i}^{D}}{2}
$$

The resolution of the system allows computing the optimal price of securities settlement, $p_{i}^{S *}$, relative to depository price, $p_{i}^{D *}$ :

$$
p_{i}^{S *}=\frac{T}{3}+\frac{1}{5}\left(3 c_{i}+c_{j}+c_{k}\right)-p_{i}^{D *}
$$

The overall price of post-trading services $\left(p_{i}^{S *}+p_{i}^{D *}\right)$ is higher than expected in a competitive market (i.e. marginal cost pricing). We find a classical result of spatial competition models, which highlights the market power created by the differentiation of products. The competitive price is increased by an amount equal to the travelling cost $\frac{T}{3}$ (i.e. the market power of each CSD on its "local" market). Thus, the differentiation between the services offered by each CSD weakens competition between them. If the CSDs are identical (i.e. have the same cost or the same size), they establish the same overall price. However, this configuration does not necessarily imply a unique pricing policy (separately for the settlement and the depository services). It can be very variable from one CSD to another. Thus, a CSD may, for example, heavily subsidize the settlement activity by shifting the full extra cost associated to its market power in the service of depository. The choice of tariff policy will determine thereafter the extent of price decrease. We will therefore study the evolution of the overall price of post-trading services rather than separate prices.

It is interesting to note that a smaller CSD will have to bear higher costs which will have the following effects on prices. On one hand, it will set a higher overall price than its competitors which makes the CSD losing market shares and reduces its profits. On the other hand, the competitors will benefit from inefficient CSD, as their overall price depends positively on the cost of all the CSDs. Thus, an inefficient CSD leads to higher overall prices on European post-trading markets.

The optimal quantities sold by the three CSDs will depend on the difference between their variable costs. A CSD with higher costs than its competitors gets smaller market shares and lower profits:

$$
q_{i}^{S^{*}}=q_{i}^{D^{*}}=N\left(\frac{c_{j}+c_{k}-2 c_{i}}{5 T}\right)+\frac{N}{3}
$$


The CSDs will get the same market shares and profit if they have the same marginal costs. When the most efficient CSD will bear a lower marginal cost than its competitors, it will capture a market share greater than one third, this on both markets.

$$
\pi_{i}^{*}=\frac{N}{T}\left(\frac{c_{j}+c_{k}-2 c_{i}}{5}+\frac{T}{3}\right)^{2}-C_{i}
$$

We can note that identical CSDs ${ }^{9}$ obtain an equal share of the market $\left(\frac{N}{3}\right)$ and profits $\left(\frac{T N}{9}-C\right)$. If one CSD has higher depository prices, it has lower settlement prices and the overall price is equal for the 3 CSDs to $\left(\frac{T}{3}+c\right)$. Thus, all the CSDs obtain a margin of $\left(\frac{T}{3}\right)$, corresponding to one third of the total travelling cost.

\subsection{Compatibility of the securities settlement services}

We investigate the case where all CSDs decide to join the platform and make their settlement systems compatible. This design gives us two market sharing conditions, because post-trading operations are still complementary but they can be bought from different CSDs. For securities settlement, which becomes a compatible service between the three CSDs, the rule of market sharing becomes:

$$
k(3)+p_{i}^{S}+t^{S} \min \left(x ; \frac{1}{3}-x\right)=k(3)+p_{j}^{S}+t^{S} \min \left(x ; \frac{1}{3}-x\right)
$$

For the settlement, the extra cost is $\mathrm{k}(3)$, because banks can buy settlement services from any CSD. Hence, they set the same prices, $p_{i}^{S}=p_{j}^{S}$, as they face a fierce price competition (Bertrand competition type) and they get one third of the total settlement market $\left(\frac{N}{3}\right)$. In such a bilateral competition design, one should observe a rapid convergence of prices towards marginal cost as, being the cheapest CSD allows it to capture two thirds of the market shares ${ }^{10}$. In this particular configuration, it is difficult to imagine that CSDs, with very different sizes, remain on the market settlement. While Bertrand's paradox applies, the CSDs, which will be disadvantaged by their costs structure, will either leave this market or will strongly support this activity with their margins on depository activity. This last case is not feasible as such a choice will only reduce their total profits without providing further earnings because of the separation of settlement and depository services. Another possibility is to assume that the CSDs may tacitly agree on a price above their marginal cost, thus enabling less efficient CSDs to maintain themselves on settlement market. A final situation can appear: if only one CSD remains on the settlement market, it will be the most

\footnotetext{
${ }^{9}$ Identical CSDs have same costs, so that $c_{i}=c_{j}=c_{k}=c$ and $C_{i}=C_{j}=C_{k}=C$

${ }^{10}$ Market shares should depend on the of the competition organisation among CSDs : either they compete two by two or all together. In multilateral competition, one could suppose that a small price cut would have dramatic impacts on market shares' distribution, the cheapest seller winning the whole market.
} 
efficient (i.e. with the lowest cost). The entry deterrence strategy of the incumbent CSD would then rely on low prices. ${ }^{11}$.

On depository services market, we set:

$$
k(1)+p_{i}^{D}+t^{D} y=k(1)+p_{j}^{D}+t^{D}\left(\frac{1}{3}-y\right)
$$

for CSD $\mathrm{i}$ in competition with $\mathrm{j}$. We can note that the extra-cost is $\mathrm{k}(1)$, because banks need to go through to their correspondant bank to record foreign security.

The total quantities are :

$$
q_{i}^{D}=\frac{N}{3}+\frac{N}{2 t^{D}}\left(p_{j}^{D}+p_{k}^{D}-2 p_{i}^{D}\right) \text { and } q_{i}^{S}=\frac{N}{3}
$$

The first rank conditions give us the following reaction function of the rational CSD $i$ :

$$
p_{i}^{D}\left(p_{j}^{D}, p_{k}^{D}\right)=\frac{t^{D}}{6}+\frac{p_{j}^{D}+p_{k}^{D}}{4}+\frac{u c_{i}}{2}
$$

The resulting optimal prices of the depository service depend only of a weighted average of the variable costs and banks' travelling costs for this service:

$$
p_{i}^{D *}=\frac{t^{D}}{3}+\frac{u\left(3 c_{i}+c_{j}+c_{k}\right)}{5}
$$

The depository price depends strongly on a substitution effect $\left(t^{D}\right.$, the travelling cost associated with the depository services). When $t^{D}$ is high, it is very expensive for banks to change their CSD and this effect is small. Thus, there is a lot of inertia on such a market: the depository price is higher than before and moves away from efficient price. On the contrary, when $t^{D}$ is low, banks easily change their CSD (almost no extra cost for switching) and the competitive price applies.

However, we should underline that, on such a market, the offer is concentrated with few CSDs, which know each others well, so we can't rule out tacit collusion. Banks continue to deal with the same CSD for the depository service and rivalry is strong less. So, it may induce collusion behaviour from CSDs on the depository activity. And the depository price converges up to $\frac{t^{D}}{3}+u c$ for identical CSDs. Assuming a Bertrand competition, the settlement price converges to $v c$. The prices are identical between the compatible CSDs for the two services: $p_{1}^{D}=p_{2}^{D}=p_{3}^{D}$ and $p_{1}^{S}=p_{2}^{S}=p_{3}^{S}$. The evolution of each price resulting from the compatibility of settlement systems depends on crosssubsidies between the settlement and the depository services pre-existing in incompatible design. If the settlement price was more or less subsidized by the depository service, it will decrease

\footnotetext{
${ }^{11}$ If it sets higher prices, the less efficient CSDs will enter on its market.
} 
(respectively more or less) with the T2S platform. The depository price may decrease or increase for the same reasons. As there is an indetermination on the prices structure before T2S starts, it is mathematically impossible to conclude now for each price. But if the depository price decreases, it will decrease less than the settlement price, because the competition is less strong on this activity. It might increase if it was hardly subsidized without the shared platform.

The overall price of the two services is equal to $\frac{t^{D}}{3}+c$. The CSD can charge only one third of the travelling cost for the depository service and cannot invoice the cost of settlement, contrary to the incompatible case. The part of complexity costs, which can be invoiced to banks, is lower than the costs without the platform. The overall price is lower because the compatibility of the settlement systems makes competition stronger. But this impact is restricted by inertia on securities. Banks do not easily modify their portfolio structure and their "natural" CSD.

The optimal depository services sold by a CSD decrease at constant rate $\frac{N}{5 t^{D}}$, when the CSD's variable costs are higher than the average cost of its rivals:

$$
q_{i}^{D^{*}}=\frac{N}{5 t^{D}} u\left(c_{j}+c_{k}-2 c_{i}\right)+\frac{N}{3}
$$

If CSDs are identical, the three one's are sharing equally the depository market as before the T2S creation. It is interesting to underline that an equal market sharing on settlement leads to an increasing profit function in $p_{i}^{S}$; thus the higher the settlement prices are, the higher the benefits are. But, they must be equal; otherwise the CSD with the higher price loses its entire market share. The CSD i's profit will be:

$$
\pi_{i}^{*}=t^{D} N\left(\frac{u}{5 t^{D}}\left(c_{j}+c_{k}-2 c_{i}\right)+\frac{1}{3}\right)^{2}+\frac{N}{3}\left(p_{i}^{S}-v c_{i}\right)-C_{i}
$$

In a contestable market, the settlement prices should be close to the marginal cost and the uncompetitive CSDs leave the settlement market. With identical CSDs, the profit will be equal to $\frac{t^{D} N}{9}-C$ and will decrease of $t^{S} N / 9$, with the adoption of T2S. But if the CSDs are able to maintain the settlement prices higher than $v c_{i}$, thanks to collusion, the profit will increase.

\subsection{Partial compatibility of the securities settlement services}

In this section, we assume that the CSDs 1 and 2 become members of the platform and that the third one (CSD 3) stays outside, i.e. it remains incompatible with the two others. For the two compatible CSDs, the market sharing corresponds to:

$$
\begin{gathered}
k(1)+p_{i}^{D}+t^{D} y=k(1)+p_{j}^{D}+t^{D}\left(\frac{1}{3}-y\right) \\
k(2)+p_{i}^{S}+t^{S} \min \left(x ; \frac{1}{3}-x\right)=k(2)+p_{j}^{S}+t^{S} \min \left(x ; \frac{1}{3}-x\right)
\end{gathered}
$$


We find the number of operations for the CSD i in competition with $\mathrm{j}: q_{i, j}^{D}=\frac{N}{6}+\frac{N}{2 t^{D}}\left(p_{j}^{D}-p_{i}^{D}\right)$ and $q_{i, j}^{S}=\frac{N}{6}$, with $i, j=1,2$ and $i \neq j$ and with $p_{i}^{S}=p_{j}^{S}$.

For the "off T2S" CSD, we can notice that the depository and settlement services are buddling goods and that banks must buy them to the same CSD 3 , so that $q_{3}^{S}=q_{3}^{D}$. The market sharing leads to the following results:

$$
k(2)+k(1)+p_{1}^{D}+p_{1}^{S}+\left(t^{D}+t^{S}\right) \frac{q_{1,3}}{N}=2 k(1)+p_{3}^{D}+p_{3}^{S}+\left(t^{S}+t^{D}\right)\left(\frac{1}{3}-\frac{q_{1,3}}{N}\right)
$$

We note $K=k(1)-k(2)$, the network externality of compatibility. This externality reflects the expected benefit for the settlement services of a larger network and it constitutes a source of differentiation among identical CSDs. A bank can either decide to settle its foreign securities to the compatible CSD or to buy this service to the incompatible CSD. The extra quality of a compatible CSD equals the savings in the extra cost generated by the cross-border transactions. More precisely, this network effect is the travelling cost savings realised by a bank, when it uses the services of a compatible CSD.

$$
K+p_{3}^{D}-p_{1}^{D}+p_{3}^{S}-p_{1}^{S}+\frac{t^{S}+t^{D}}{3}=2\left(t^{S}+t^{D}\right) \frac{q_{1,3}}{N}
$$

The resulting quantities for the depository and settlement services are reported in the appendices. One obtains the following optimal prices values $p_{i}^{S *}$ for the settlement :

$$
\begin{aligned}
& p_{i}^{S *}=\frac{K}{3}+\frac{v}{12}\left[7 c_{i}+c_{j}+4 c_{3}\right]+\frac{5}{9} T \\
& p_{3}^{S *}=-\frac{K}{3}-p+\frac{1}{6}\left(c_{1}+c_{2}+4 c_{3}\right)+\frac{4}{9} T
\end{aligned}
$$

with $i, j=1,2$ and $i \neq j$ for the compatible CSDs. ${ }^{12}$. The prices of the depository service are $p_{i}^{D *}=\frac{u}{3}\left(2 c_{j}+c_{i}\right)$ and $p_{3}^{D *}=p$. The compatible CSDs 1 and 2 benefit from a comparative advantage over their competitor (CSD 3), resulting in an increase in their market power, which makes their settlement price increasing of $K / 3$. At the opposite, the CSD 3 is penalised and must somehow offer some compensation to banks which buy its services, by giving them lower prices (reduced of $-K / 3$ ). If $\mathrm{K}$ is enough large (i.e. $K>\frac{4}{3} T$ ) then the CSD 3 is simply excluded from the market.

The market shares depend on the size of the T2S network in regards of the substitution effect $\left(t^{D}\right.$, i.e. the fact that a bank decides to change the CSD which records its securities ${ }^{13}$. On the T2S system, the increasing market shares make the CSDs less aggressive, but so, the CSDs become

\footnotetext{
${ }^{12} \mathrm{We}$ adopt the same notation for all the following equations.

${ }^{13}$ Note that in this case, it implies that the bank changes its securities portofolio. Some securities dealed by CSDs are very close according to their intrinsec characteristics, such as liquidity, interest rate and risk. For example, the French and German Treasury bonds are not very different, so that banks are rather indifferent between these two products. Competition between "in" and "off" CSDs could be strong, when products are rather sustituable and the "on T2S" CSDs can compete easily the "off CSD" on its natural market.
} 
better substitutes. This situation is reinforcing competition between them. This leads them to equal the depository price to their marginal cost and to increase the settlement price.

The equilibrium quantities are respectively :

$$
\begin{gathered}
q_{i}^{S *}=\frac{N}{2 T}\left[\frac{K}{3}+\frac{5 T}{9}+\frac{1}{12}\left(c_{j}+4 c_{3}-5 c_{i}\right)\right]+\frac{N}{3} \\
q_{i}^{D *}=q_{i}^{S *}+\frac{u N}{6 t^{D}}\left(c_{j}-c_{i}\right) \\
q_{3}^{S *}=q_{3}^{D *}=\frac{4 N}{9}+\frac{N}{2 T}\left[-\frac{2 K}{3}+\frac{1}{3}\left(c_{1}+c_{2}-2 c_{3}\right)\right]
\end{gathered}
$$

and the equilibrium profits :

$$
\begin{aligned}
\pi_{i}^{*} & =\frac{N}{2 T}\left\{\left[\frac{K}{3}+\frac{c_{j}+4 c_{3}-5 c_{i}}{12}+\frac{5}{9} T\right]^{2}+\frac{u^{2}}{9}\left(c_{j}-c_{i}\right)^{2}\right\}-C_{i} \\
\pi_{3}^{*} & =\frac{N}{T}\left[\frac{c_{1}+c_{2}-2 c_{3}}{6}-\frac{K}{3}+\frac{4}{9} T\right]^{2}-C_{3}
\end{aligned}
$$

For identical CSDs, the overall price of an operation increases, from $\frac{T}{3}+c$ to $\frac{K}{3}+c+\frac{5 T}{9}$ in $\mathrm{T} 2 \mathrm{~S}$ and to $-\frac{K}{3}+c+\frac{4 T}{9}$ out of T2S. Some banks have a preference for a network service and they accept higher prices on T2S. The adoption of T2S leads to equal quantities of settlement and depository services for compatible CSDs, but they are lower than before T2S if the network effect is not very large, i.e. if $K<\frac{T}{3}$. A compatible CSD looses some customers but its margin increases. The CSDs do not want to provoke a price war, which could be destructive. So starts a collusion between the two compatible CSDs on higher prices. The incompatible CSD acts as a follower and gets benefits to stay incompatible, if the network effect is not sufficient to convince banks of changing its CSD; its market sharing increases. The settlement price will increase on T2S (comparing with the situation before T2S), because the network effect makes this service on the platform more attractive. Banks have interest in aggregating their settlement operations in one CSD and they accept that the settlement price grows up. The extent of the increase depends on the cross-subsidies existing before T2S. For the depository service, we observe a decrease which may be significant. Indeed, we can suppose that the competition is harder for the depository activity and that the CSDs are more aggressive on this service. There is no compatibility on the depository activity: the off CSD needs to attract banks on this service to minimize the lost of market shares.

In both cases, if a compatible CSD has a lower cost than its compatible and incompatible rivals, then its profit is higher because the quantity increase dominates the price decrease (with $u<\frac{7}{8}$ ). 
These cost differences will be reinforced by the size of the transportation costs. For identical CSDs, the quantities are decreasing, if the network effect is not very large $\left(K<\frac{T}{3}\right)$.

\section{Which compatibility design for the European settlement systems?}

From the EBC point of view, the T2S platform will put the settlement systems of its CSDs members in competition. Thus, this situation could be not profitable for all of them. One should observe a conflict between the ECB and the CSDs interests. In the following paragraph, the point 4.1 will present the ECB point of view, comparing the overall price of post-trading and the CSDs' profit, according to the configuration of the settlement system. In the point 4.2 , we will introduce a second stage in our game in order to analyse the strategic choice of the CSDs to join or not the $\mathrm{T} 2 \mathrm{~S}$ system.

\subsection{The ECB point of view}

The main target of the ECB is to reduce the cost of post-trading for banks. Thus, we need to compare the overall prices in the different settlement designs (refer to the different prices in Table 1). It is easy to show that for $K<\frac{4}{3} T$, we obtain the following overall prices order for the CSDs 1 and $2: C<I C<P C^{14}$.

\begin{tabular}{|c|c|c|}
\hline Compatibility designs & CSDs 1 and 2 & CSD 3 \\
\hline IC & \multicolumn{2}{|c|}{$\frac{T}{3}+c$} \\
\hline C & \multicolumn{2}{|c|}{$\frac{t^{D}}{3}+c$} \\
\hline PC & $\frac{K}{3}+c+\frac{5}{9} T$ & $-\frac{K}{3}+c+\frac{4}{9} T$ \\
\hline
\end{tabular}

Table 1: Overall prices in the different settlement designs

This target is realised if and only if all CSDs join T2S (case C). At the opposite, if and if only the CSDs 1 and 2 adhere to T2S, it is the worst situation for banks (case PC) because the prices will increase.

One crucial point of our results is that the CSDs' profit shouldn't incite them to adopt T2S. We can easily conclude that for the CSDs 1 and 2, we obtain the following profits order: $C<I C<P C$ (see table 2).

\begin{tabular}{|c|c|c|}
\hline Compatibility designs & CSDs 1 and 2 & CSD 3 \\
\hline IC & \multicolumn{2}{|c|}{$\frac{T}{9} N-C_{i}$} \\
\hline C & \multicolumn{3}{|c|}{$t^{D} \frac{N}{9}-C_{i}$} \\
\hline PC & $\frac{N}{2 T}\left[\frac{K}{3}+\frac{5}{9} T\right]^{2}-C_{i}$ & $\frac{N}{T}\left[-\frac{K}{3}+\frac{4}{9} T\right]^{2}-C_{3}$ \\
\hline
\end{tabular}

\footnotetext{
${ }^{14}$ Note that if this condition is not satisfied, the CSD 3 is excluded from the settlement market
} 
Table 2 : Profits in the different settlement designs.

If the settlement compatibility was complete (case C), then the CSDs would no longer benefit from a network effect because they would offer the same service to all the banks. When all the CSDs make their settlement systems compatible, they also loose a part of their market power, because they offer the same service. Suppose now at the opposite that the compatibility design (case C) would enable the CSDs to obtain higher profits. This result would imply that the settlement prices should be higher than their marginal costs, plus the average settlement transportation costs. This situation is reflecting the CSDs' market power (i.e. $p_{i}^{S}>\frac{t^{S}}{3}+v c_{i}$ ). In this situation, the settlement market would be highly collusive. And the prices would be higher than what would allow the services differentiation. The European authorities would not allow such an increase in the global pricing due to tacit collusion. On a non-collusive market, prices are identical and converge to the marginal costs. So, in the case C, the CSDs' earnings are always lower than in the case IC. Note that this result partly reflects the barriers to unification of the European post-trading. The compatibility does not allow identical CSDs to charge different prices on the settlement and this competition leads to sharp price cut, reducing their profits. Thus, they have an interest to differentiate themselves, either by refusing to join T2S (case IC) or ensuring themselves that some CSDs will remain outside the platform (case PC). Therefore, we need to understand why one CSD may be reluctant to join the shared platform (i.e. the incentive of the CSD 3 to be on the T2S platform).

In the case $\mathrm{PC}$, if $K>\frac{4 T}{3}$, the CSD 3 is excluded from the market of the settlement and depository services and the CSDs 1 and 2 capture the whole market. If the network effect is rather important $\left(\frac{4 T}{3}-\sqrt{T t^{D}}<K<\frac{4 T}{3}\right)$, the CSD 3 stays on the market and decides to adopt T2S $(P C<C<I C$, for its profit); it obtains one third of the market share (see table 3 ).

\begin{tabular}{|c|c|c|}
\hline Compatibility design & CSDs 1 and 2 & CSD 3 \\
\hline IC & \multicolumn{2}{|c|}{$\frac{N}{3}$} \\
\hline C & \multicolumn{2}{|c|}{} \\
\hline PC & $\frac{N}{2 T}\left(\frac{K}{3}+\frac{5 T}{9}\right)$ & $\frac{N}{T}\left(\frac{4 T}{9}-\frac{K}{3}\right)$ with $K<\frac{4}{3} T$ \\
\hline
\end{tabular}

Table 3 : Market shares in the different settlement designs

If the network effect is a bit lower $\left(\frac{T}{3}<K<\frac{4 T}{3}-\sqrt{T t^{D}}\right)$, the CSD 3 decides to not join T2S $(C<P C<I C)$ and it will capture a lower market share than in the compatible design. In that case, T2S obtains more than $2 / 3$ of the whole market. In the last case $\left(K<\frac{T}{3}\right)$, the CSD 3 makes the same decision and prefers staying off T2S $(C<I C<P C)$; its market share is higher and particularly higher than $1 / 3$. So, the more important is $\mathrm{K}$ and the smaller is $\mathrm{T}$, the more the CSD 3 will have incentives to integrate the shared platform. We can notice that if a European CSD prefers to maintain its market shares, its decision will depend on the $\mathrm{K}$ value. If the other CSDs adopt T2S, it will so be reluctant to join T2S when $K<\frac{T}{3}$ and will prefer to be member of T2S when $K>\frac{T}{3}$. If the off-Euro zone CSDs were authorized or encouraged to integrate the platform, especially the Scandinavian countries, Switzerland and United Kingdom, their decision 
would certainly depends on their expected market shares losts and of the $\mathrm{K}$ value (which will be determinant for the $\mathrm{T} 2 \mathrm{~S}$ attractivity).

When comparing prices between the incompatibility and the partial compatibility of the CSDs, we observe that the settlement prices should decrease on the platform to get a rather high network effect (i.e. $K>\frac{T}{3}$ ), but one obtains an increase in the overall price. If all the CSDs join the shared platform, the overall price decrease may not be achieved because of collusion. Thus, the opening to competition of the settlement services, by making their settlement systems compatible, may not imply a decrease of the post-trading prices in the Euro zone. So, the ECB may consider regulating the settlement price either by a unique price per operation official for all the parties, or by a non linear pricing based on banks sizes.

\subsection{Will the T2S platform be adopted by the CSDs ?}

As mentioned previously, the ECB decided to unify one part of the European financial post market through the adoption of T2S in 2014. However, the ECB would prefer a voluntary adoption of T2S by CSDs to force them to standardized their settlement system. Thus, it remains interesting to adress the question of the incentive of the CSDs to join the commun settlement system. Will the T2S platform be adopted by the CSDs? To evaluate the attraction of this shared platform of settlement, we compute Nash Equilibrium resulting from the previous institutional designs. For simplicity, we assume that the CSDs are identical (i.e. $c_{1}=c_{2}=c_{3}$ and $F_{1}=F_{2}=F_{3}=F$ ).

Therefore, the CSDs are involved in a two stages game. At stage one, each CSD decides simultaneously to become (or not) compatible on the settlement market with its rivals. So, we obtain one of the three market designs discussed in point 3. If each CSD chooses the compatibility strategy $\left(C_{1}, C_{2}, C_{3}\right)$, there is a unique settlement market. If only two CSDs decide to be compatible, the compatibility is incomplete and one CSD remains outside the settlement platform, $I C_{i}$. Finally, if no CSD (or only one) chooses the compatibility strategy, there is no settlement platform and the settlement services are incompatible between the CSDs. At stage two, given the market design, the three CSDs set simultaneously and independently their prices for settlement and depository in order to maximise their profits, which are reported in the matrix payment of Table 4 (see the point 3 for the profit computation according to the market design of settlement). Thus, the CSDs are involved in a three players games, named the compatibility game in the following. It can be summarized by $\left\langle N=3,\left(C_{i}, I C_{i}\right), \pi=\left(\pi_{i}\right)\right\rangle$, which the issues correspond to our three compatibility designs (Compatibility for $C_{i}, C_{j}, C_{k}$, Incompatibility for $I C_{i}, I C_{j}, I C_{k}$ or $C_{i}, I C_{j}, I C_{k}$ and Partial Compatibility for $I C_{i}, C_{j}, C_{k}$ ). The resolution of this game depends on the different profits order, which relies on $K$, the relative network strenght in partial compatibility, on $T$ the level of service differentiation and on $t^{D}$, the substitution effect. 


$\mathrm{C}_{3} \quad \mathrm{IC}_{3}$

\begin{tabular}{|c|c|c|c|}
\hline \multicolumn{2}{|c|}{ CSD 2} & \multicolumn{2}{|c|}{ CSD 2} \\
\hline$C_{2}$ & $I C_{2}$ & $C_{2}$ & $I C_{2}$ \\
\hline$A, A, A$ & $B, C, B$ & $B, B, C$ & $D, D, D$ \\
\hline
\end{tabular}

CSD 1

$$
I C_{1} \quad C, B, B \quad D, D, D \quad D, D, D \quad D, D, D
$$

Table 4: The compatibility game with $A=\frac{t^{D}}{9} N-F$, $B=\frac{N}{2 T}\left[\frac{5}{9} T+\frac{K}{3}\right]^{2}-F, C=\frac{N}{2 T}\left[\frac{5}{9} T+\frac{K}{3}\right]^{2}-F, D=\frac{T}{9} N-F$

For all values of $K$, the incompatible market design is always a Nash equilibrium of the game, ie. $\pi_{i}\left(I C_{i}^{*}, I C_{j}^{*}, I C_{k}^{*}\right)>\pi_{i}\left(C_{i}, I C_{j}^{*}, I C_{k}^{*}\right)$. But, it is not the unique one. The remaining equilibrium will depend on the success of T2S and more specifically on its network effect that might be low with $K<\frac{T}{3}$, medium with $\frac{T}{3}<K<\frac{4}{3} T-\sqrt{T t^{D}}$ or high with $\frac{4}{3} T-\sqrt{T t^{D}}<K<\frac{4}{3} T$.

In case of a low or medium network effect, the partial compatible designs are also Nash equilibrium of the game with $\pi_{i}\left(C_{i}^{*}, C_{j}^{*}, I C_{k}^{*}\right)>\pi_{i}\left(I C_{i}, I C_{j}^{*}, I C_{k}^{*}\right)$ and $\pi_{i}\left(I C_{i}^{*}, C_{j}^{*}, C_{k}^{*}\right)>\pi_{i}\left(C_{i}, C_{j}^{*}, C_{k}^{*}\right)$ for each CSD $i^{15}$. For low network effect, CSDs face a severe coordination problem as each of them will be the one who prefers being the incompatible one. Such that coordination failures should lead to the selection of the incompatibility design with lower profits for all the CSDs. On the opposite, for medium network effect, the CSDs will prefer to be compatible rather than incompatible in the partial compatibility designs. So, coordination default could end on any possible outside equilibrium paths.

In case of high network effect, the alternative Nash equilibria of the game is the adoption of T2S by all CSD with $\pi_{i}\left(C_{i}^{*}, C_{j}^{*}, C_{k}^{*}\right)>\pi_{i}\left(C_{i}, I C_{j}^{*}, I C_{k}^{*}\right) .{ }^{16}$. In that case, the CSDs play a coordination game with a Pareto ranking of the equilibrium, the incompatibility market design being the Pareto dominant. According to Camerer 2003, Pareto dominance criterium might help CSDs to coordinate on the incompatible market design. Thus, one may also not observe a volontary adoption of T2S by the CSDs.

Does collusion on settlement price has an impact on the equilibrium of our game $?^{17}$ The answer depends also on the network effect of T2S. Collusion has only an impact in case of medium and

\footnotetext{
${ }^{15}$ This result holds on the following profit order $A<D, D<C$ and $C<B$ for all CSDs. Note that, in this case, the partial compatibility is Pareto-dominant. Whereas, for $\frac{T}{3}<K<\frac{4}{3} T-\sqrt{T t^{D}}$, the profit order is equal to $A<B, D<C, B<C$ and $B<D$. Thus, the more desirable situation is to be a compatible CSD in the partial compatibility design.

${ }^{16}$ For $\frac{4}{3} T-\sqrt{T t^{D}}<K<\frac{4}{3} T$, the profit order differs as the compatibility is the less desirable issue as $A<D, D<C$ and $B<C$ for all CSDs.

${ }^{17}$ The CSDs set the same price for settlement in the compatible and the incompatibility configurations to maximize their collective profit (see point 3.2). Note that earnings A become $\frac{T}{9} N-F$ instead of $\frac{t^{D}}{9} N-F$ in the general case.
} 
high network effects. In those situations, compatible and incompatible designs become the two equilibria of the compatibility game ${ }^{18}$ with $\pi_{i}\left(I C_{i}^{*}, I C_{j}^{*}, I C_{k}^{*}\right)>\pi_{i}\left(C_{i}, I C_{j}^{*}, I C_{k}^{*}\right)$ for the incompatible equilibrium and $\pi_{i}\left(C_{i}^{*}, C_{j}^{*}, C_{k}^{*}\right)>\pi_{i}\left(C_{i}, I C_{j}^{*}, I C_{k}^{*}\right)$ for the compatible equilibrium. The CSDs face a pure coordination game as $\pi_{i}\left(C_{i}^{*}, C_{j}^{*}, C_{k}^{*}\right)=\pi_{i}\left(I C_{i}^{*}, I C_{j}^{*}, I C_{k}^{*}\right)$. Once more, it will be difficult for the CSDs to select one equilibrium.

To sum up, in most situations the CSDs will face a severe coordination problem because of multiplicity of the equilibria, such that compatible or partial market design may be unlikely even for the higher values of $K$. One solution could be a ECB regulation to prevent a new failure of the unification of the European financial post-market.

\section{Conclusion}

In this article, we have analysed the effects of the introduction of Target 2 Securities in terms of pricing, market shares and market structures. The main difficulty relies on the current lack of transparency on the separate prices of each service as pointed out in the incompatible case. Therefore, one can conclude that the overall price for settlement and depository services will decrease if all CSDs join T2S. However, this result strongly depends on the market contestability. In case of partial compatibility, the network effect of T2S is determinant for a price decrease. Under certain conditions, partial adhesion would make prices increase and this configuration appears as a Nash equilibrium. This result implies that the ECB might be forced to regulate.

What will be the size of T2S if CSDs are free to adhere to T2S ? The relative strongness of the substitution effect over the network effect determines the T2S attractivity in the partial compatibility design. A weak network effect will lead to partial compatibility and let the off-Euro zone CSDs outside T2S. Countries, such as the Scandinavian countries, Switzerland and United Kingdom, will adhere to T2S only in case of strong network effect. However, whatever is the network force, incompatibility can never be excluded. Once more, the ECB could be forced to oblige the Euro zone CSDs to join T2S.

Some questions are remaining opened and they should be thorough investigated. Firstly, fix costs could be less important on T2S, so that it could make the platform more attractive. Secondly, even if CSDs were identical in terms of operations market shares, one could imagine that they would have more or less concentrated customers, so that they would uphold different marginal access costs to T2S. Thirdly, one could think that securities may be more or less substitutable, and that the resulting competition could increase or decrease the prices

\section{Acknowledgements}

We have benefited from discussions with Marc Bayle (ECB), Marc Tibi (BNP Paribas), Pierre Slechten (Euroclear France) and seminar participants at GATE. Helpful comments were received

\footnotetext{
${ }^{18}$ This result holds on the following profit order $A<=D, A>C$ and $A<B$ for all CSDs.
} 
from discutants of the 8th INFINITI Conference on International Finance at Trinity College Dublin. The financial support from "Chaire universitaire of Lyon 2 University in Experimental Economics" is gratefully acknowledged. All mistakes remain our own. The views expressed are those of the authors and do not necessarily reflect the views of the mentioned institutions.

\section{References}

[1] Bouckaert, J., Degryse, H., 1995. Phonebanking, European Economic Review, 39, 229-244

[2] Camerer, C., 2003. Coordination. In: Behavioral Game Theory. Princeton University Press: Princeton, New Jersey.

[3] Giovannini Group, 2001. Cross-border clearing and settlement arrangements in the European Union, European Commission Economic Papers.

[4] Giovannini Group, 2003. Second report on UE clearing and settlement arrangements, European Commission Economic Papers.

[5] Grant J., Demos T., Wilson J., 2011. Deutsche Börse and NYSE Unveil Deal Terms, Financial Times, February 15.

[6] Kauko, K., 2004, The links between international securities settlement systems: An oligopolistic theoretic approach, International Review of Financial Analysis 13, 585-600.

[7] Lannoo and Levin, 2001. The securities settlement industry in the EU - Structure, costs and the way forward", Discussion paper, CEPS.

[8] Matutes C., Padilla J-A., 1994. Shared ATM networks and banking competition, European Economic Review 44, 917-927.

[9] Salop S., 1979. Monopolistic competition with outside goods, Bell Journal of Economics 101, 141-156.

[12] Serifsoy, B., Weiss, M., 2007. Settling for efficiency - A Framework for the European securities transactions industry, Journal of Banking and Finance 31, 3034-3057.

[13] Schmiedel, H., Malkamaeki, M., Tarkka, J., 2006. Economies of scale and technological development in securities depository and settlement systems, Journal of Banking and Finance 30, $1783-1806$.

[14] Schmiedel, H., Schoenenberger A., 2005. Integration of securities market infrastructures in the Euro area, European Central Bank Occasional Paper 33.

[15] Van Cauwenberge, S., 2003. New structure for clearing and settlement systems in the EU, Financial Stability Review NBB, 83-103. 
[15] Van Cayseele, P., Wuyts, C., 2007. Cost efficiency in the European securities settlement and safekeeping industry, Journal of Banking and Finance 31, 3058-3079.

\section{Figure 1}

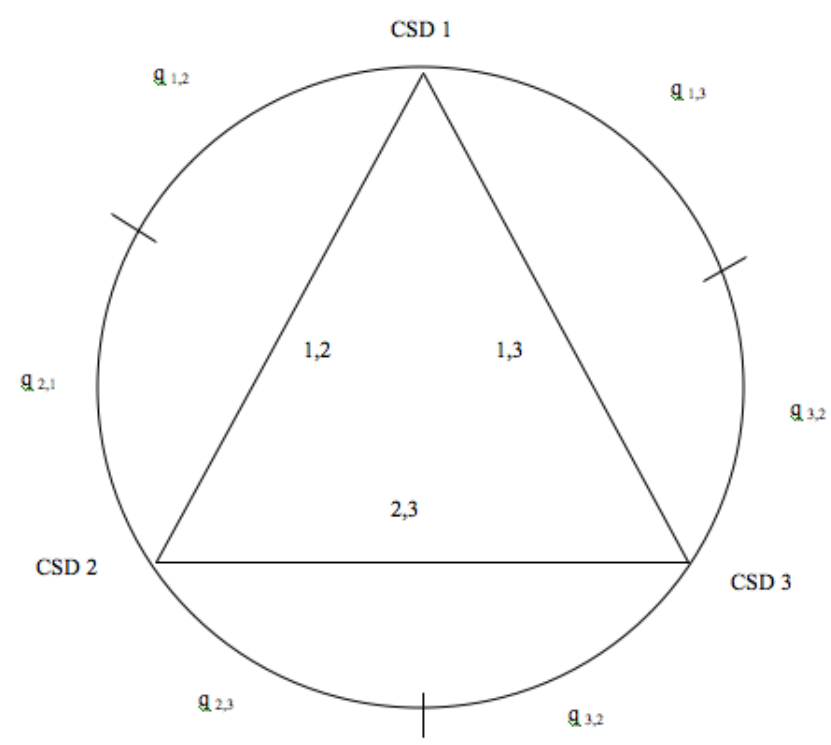

